\title{
Reply to "Ground Glass Opacity (GGO) Predicts Improved Survival of Pathologic Stage I Lung Adenocarcinoma Patients" by Guowei Che et al.
}

\author{
Shunsuke Shigefuku, MD, PhD (1) \\ Department of Surgery, Tokyo Medical University, Tokyo, Japan
}

\section{Dear Editors}

We appreciate you inviting us to reply to the letter by Che et al. ${ }^{1}$ and greatly thank Che and colleagues for their comments.

In our study, we retrospectively reviewed 936 patients who survived for 5 years after complete resection of lung adenocarcinoma. We indicated that the absence of ground glass opacity (GGO) components was significantly associated with overall suvival $(p<0.01)$ and cancer-specific survival $(p<0.01)$ in 5-year survivors with stage I disease $(n=782)$. In addition, the recurrence rates of 5-year survivors without GGO components were significantly higher than those with GGO components at any time point during the 10-year postoperative follow-up period. Therefore, these results suggest a biological difference in carcinogenesis, depending on the presence or absence of radiological GGO components. ${ }^{1}$ We expect further investigation to clarify the mechanism of lung adenocarcinoma with or without GGO components from the viewpoint of molecular biology.

Owing to the recent advances in clinical imaging techniques such as high-resolution computed tomography (HRCT), we were able to conduct easy analysis to estimate the existence of GGO components in tumors. Recently, several studies have shown that the presence of GGO components itself was associated with a more favorable prognosis than the absence of GGO components in early-

(C) Society of Surgical Oncology 2021

First Received: 30 April 2021

Accepted: 1 May 2021;

Published Online: 15 June 2021

S. Shigefuku, MD, $\mathrm{PhD}$

e-mail: ssshigefukuuu8888@gmail.com stage non-small cell lung carcinoma, particularly in lung adenocarcinoma. ${ }^{3,4}$ Miyoshi et al. revealed that the presence of radiological GGO components in resected lung adenocarcinoma was more reflective of survival outcomes than the presence of a pathological lepidic-growth component in patients with pathological stage IA. ${ }^{5}$ It is valuable to be able to predict the prognosis of lung adenocarcinoma prior to surgery for surgeons who select surgical procedures such as lobectomy, segmentectomy, or partial lung resection. We believe that analysis of the existence of GGO components in tumors on computed tomography scan will play a more important role in estimating the clinical stage of lung adenocarcinoma in the future.

DISCLOSURES Shunsuke Shigefuku has no conflicts of interest to disclose.

\section{REFERENCES}

1. Wang Y, Che G, et al. Ground glass opacity predicts improved survival of pathologic stage I lung adenocarcinoma patients. Ann Surg Oncol. https://doi.org/10.1245/s10434-021-10150-7

2. Noguchi M, Morikawa A, Kawasaki M, et al. Small adenocarcinoma of the lung. Histologic characteristics and prognosis. Cancer. 1995;75:2844-52.

3. Hattori A, Matsunaga T, Takamochi K, Oh S, Suzuki K. Prognostic impact of a ground glass opacity component in the clinical T classification of non-small cell lung cancer. J Thorac Cardiovasc Surg. 2017;154:2102-2110.e2101.

4. Ye T, Deng L, Wang S, et al. Lung adenocarcinomas manifesting as radiological part-solid nodules define a special clinical subtype. J Thorac Oncol. 2019;14:617-27.

5. Miyoshi T, Aokage K, Katsumata S, Tane K, Ishii G, Tsuboi M. Ground-glass opacity is a strong prognosticator for pathologic stage IA lung adenocarcinoma. Ann Thorac Surg. 2019;108:249-55.

Publisher's Note Springer Nature remains neutral with regard to jurisdictional claims in published maps and institutional affiliations. 